\title{
Implementation of the School-Wide Positive Behavior Interventions and Supports Approach in 30 Greek primary schools
}

\section{Theodore Goutas ${ }^{1 *}$, Ioannis Trikkaliotis ${ }^{2}$, Petros Kliapis ${ }^{3}$, Athanasios Gregoriadis ${ }^{4}$, Nikolaos} Tsigilis $^{5}$, Argyris Theodosiou ${ }^{6}$, Vasilis Grammatikopoulos ${ }^{7}$

\author{
${ }^{l} P h D$ candidate, Aristotle University of Thessaloniki, Greece \\ ${ }^{2}$ Senior Education Executive for Primary School Teachers, Greece \\ ${ }^{3}$ Adjunct Lecturer, Department of Education, University of Nicosia, Cyprus \\ ${ }^{4}$ Associate professor, Department of Early Childhood Education, Aristotle University of Thessaloniki, Greece \\ ${ }^{5}$ Associate professor, Department of Journalism \& Mass Communications, Aristotle University of Thessaloniki, \\ Greece \\ ${ }^{6}$ School of Physical Education and Sports Science, Aristotle University of Thessaloniki, Greece \\ ${ }^{7}$ Professor, Department of Early Childhood Education \& Care, School of Social Sciences, International \\ Hellenic University, Greece
}

\begin{abstract}
.
The School-wide positive behavior interventions and supports (SWPBIS) approach is a threetier school-wide framework to create a safe and positive school climate, to promote student socio-emotional competencies and teacher effectiveness. The implementation of SWPBIS is related to positive outcomes such as a decrease of students' behavioral problems. SWPBIS was introduced in Greece for the first time in 2019 as part of the Erasmus+ KA3 project titled: "Building School-Wide Inclusive, Positive and Equitable Learning Environments Through A Systems-Change Approach (SWPBIS)". The purpose of this study is to describe SWPBIS's Tier 1 eight core features and to describe the training/coaching procedure of the school leadership teams. In addition, this study discusses how teachers addressed the various challenges they faced during the project's implementation in 30 Greek primary schools. Finally, recommendations for future practices are offered based on the acquired experience.
\end{abstract}

Keywords: Positive behavior, school-wide interventions, in-service training, coaching

\section{Introduction}

Discipline codes, sanctions, increased monitoring and surveillance failed to create positive climates and right sense of security in schools (Sugai \& Horner, 2002) $\square$. Furthermore, punishing problem behaviors without a positive school-wide system of support was associated with increased aggression, vandalism, truancy, tardiness, and dropouts (Colvin, Kameenui, \& Sugai, 1993; Lewis \& Sugai, 1999). 


\section{2nd world conference on research in SOCIAL SCIENCES}

19-21 March, 2021

Budapest, Hungary

Positive Behavior Interventions and Supports (PBIS) has evolved out of: (a) a need for a more proactive approach to school discipline and safety, (b) a strong behavior analytic tradition of studying and improving human behavior (Sugai \& Horner, 2002) $\square$, (c) an increased legislative pressure on schools to prevent disruptive and violent behavior (Bradshaw, Reinke, Brown, Bevans, \& Leaf, 2008), (d) the normalization/inclusion movement and (e) person-centered values $\square$ (Carr et al., 2002). The social behavioral needs of all students resulted in the evolution of School Wide PBIS (SWPBIS) by implementing empirically validated practices achieving positive school climate, important social and learning outcomes while preventing problem behavior (Sugai \& Horner, 2002) $\square$.

\section{The Erasmus+ KA3 project}

The Erasmus+ KA3 project titled: "Building School-Wide Inclusive, Positive and Equitable Learning Environments through a Systems-Change Approach" was commenced in 2019. In total, 120 schools from Cyprus, Finland, Greece and Romania participate in the implementation of the SWPBIS principles. In the fall of 2020, SWPBIS Tier 1 was introduced for the first time in 30 Greek schools by a consortium of Aristotle University of Thessaloniki and the Regional Directorate of Primary and Secondary Education of Central Macedonia. In total, 3799 students and 478 teachers from the above mentioned 30 schools participate in the project.

\section{SWPBIS's three-tier approach}

SWPBIS is based on behavioral and biomedical sciences. It is a framework with distinctive core features and standard procedures such as a three-tiered system of support, the teaching of behavior, the ongoing collection of data for decision making, and the use of evidence-based practices. The social behavioral needs of all students resulted in the evolution of SWPBIS by implementing empirically validated practices achieving important social and learning outcomes while preventing problem behavior (Sugai \& Horner, 2002). SWPBIS is defined as a three-tiered interventions model (McKevitt \& Braaksma, 2004) $\square$ used to create school climate of common behavioral expectations for all students and create systems to foster durable changes in the behavior of higher-needs students (Bradshaw, Mitchell, \& Leaf, 2010). In SWPBIS emphasis is placed on team-based coordination, investment in primary tier prevention, iterative progress monitoring, universal screening and a continuum of effective intervention options that match student needs $\square$ (Sugai \& Horner, 2008) $\square$.

SWPBIS organizes interventions along a three-tiered prevention continuum (Sugai \& Horner, 2008). $\square$ The Tier 1 or primary intervention strategy involves rearranging the school environment to enhance lifestyle and improve quality of life rather than operating directly on reducing problem behavior per se (Carr et al., 2002). It is proactive and designed to be administered before error patterns develop. It aims to establish a social culture in which students expect and support appropriate behavior from each other within a socially predictable, consistent, safe, and positive school environment (R. H. Horner et al., 2009) $\square \square \square$. Furthermore, it focuses on establishing a school-wide positive social culture that includes: (a) defining and teaching a small set of behavioral expectations for all students across non- classroom and classroom settings, (b) establishing a ubiquitous system for reinforcing performance of these expectations, (c) implementing a consistent system for 


\section{2nd world conference on research in SOCIAL SCIENCES}

19-21 March, 2021

Budapest, Hungary

interrupting, correcting, and redirecting behavioral errors, and (d) building an efficient system to collect, summarize, and use data for decision-making. All students experience Tier 1 behavior support (Horner et al., 2009; Horner \& Sugai, 2015) $\square \square \square$. Approximately 80\% to $90 \%$ of students are projected to respond successfully to the school-wide component of Tier I (Bradshaw et al., 2008).

Tier 1 will not reach the $15-20 \%$ of the student population who need more intensive intervention efforts. Tier 2 or secondary prevention practices focus on moderate intensity supports that address the most common needs of students with ongoing problem behavior. They are designed for the $10-15 \%$ of students (Bradshaw et al., 2008) $\square$ who benefit from additional structure, more overt and frequent antecedent prompts, a higher rate of positive recognition and elevated training in both behavioral expectations and self-regulation skills (Horner \& Sugai, 2015).

A $1-5 \%$ of students who enter schools with significant skills deficits do not respond to school-wide or secondary interventions and will need more intensive individualized interventions (Horner et al., 2009) $\square$ in order to succeed in school (Bradshaw et al., 2008) $\square$. Tier 3 or tertiary prevention practices are characterized by individualized assessment, individualized support plan design, comprehensive support plan implementation and the management of support by a team uniquely organized to meet the needs of individual student (Horner et al., 2009) $\square \square$.

\section{SWPBIS's Tier 1 core features}

Although SWPBIS relies on a three-tiered level preventive support on students' problem behaviors (Bradshaw et al., 2010; Horner \& Sugai, 2015), implementing Tier 1 is of critical value because the entire student population of a school is involved (Horner \& Sugai, 2015). The purpose of Tier 1 is to prevent the development of antisocial behavior but also to promote positive behavior and the cultivation of social skills by all students of a school (Barrett, Bradshaw, \& Lewis-Palmer, 2008; Horner \& Sugai, 2015). Furthermore, Tier 1 is considered a necessary step in detecting further learning difficulties of those students who will be addressed to the next two support levels (T. Lewis \& Sugai, 1999; Van Camp, Wehby, Copeland, \& Bruhn, 2020). Tier 1 has been proven a very popular intervention strategy to improve students' learning outcomes, because it requires a relatively small number of teaching staff to manage, a few hours of training of teaching staff who will implement the intervention and minimal financial resources to support it (Barrett et al., 2008). Finally, Tier 1 requires minimal hours of teaching social behaviors in the classroom (Barrett et al., 2008).

To embrace Tier 1 prevention strategies and ensure a positive and proactive approach to discipline that is likely to lead to behavioral and academic success, eight core features or components of Tier 1 implementation that form a highly effective approach to school-wide discipline have been identified (MO-SWPBS Handbook, 2020). These components include: 1) Common Philosophy and Purpose, 2) Leadership, 3) Clarifying Expected Behavior, 4) Teaching Expected Behavior, 5) Encouraging Expected Behavior, 6) Discouraging Unexpected Behavior, 7) Ongoing Monitoring, and 8) Professional Learning (MO-SWPBS Handbook, 2020). The eight Tier 1 core features are discussed in the following sections. 


\section{2nd world conference on research in SOCIAL SCIENCES}

19-21 March, 2021

Budapest, Hungary

\subsection{Common philosophy and purpose}

The first step of Tier 1 implementation includes the statement of the purpose and goals of the school regarding the creation of a common vision, i.e. the formation of an image of the school in the future which will be different and better than the one before the implementation of the intervention (T. Lewis \& Sugai, 1999; Nelen, Blonk, Scholte, \& Denessen, 2020; Yeung et al., 2016). The common vision focuses on the desired outcomes as well as school values. At the same time, it depicts the reasons, desires, values and beliefs of each school unit that distinguish it from other schools.

The common vision guides the members of the school community and answers the question: "What do we want to create?" When a school community develops and adopts a vision collectively, then the quality of interpersonal relationships between all members improve, resulting in the "school" becoming "our school" (MO-SWPBS Handbook, 2020). The vision is a picture of the future that the school community wants to create and is briefly described by two to three sentences that are clearly articulated, emphasize the positive interaction of individuals in the school environment and are oriented towards the desired results. An example of a common school vision is the following sentence: "We envision a school where we are all happy; where we are all learning, improving and growing within an environment where respect, responsibility and security are in place."

\subsection{Leadership}

Tier 1 implementation is led by a school team that assumes responsibility and authority to organize, integrate and coordinate the common effort. The goal is to establish membership and routines so that communications and representation are efficient and maximized. Hence, the school principal is invited to participate actively, providing time for meetings, training and group work for the teaching staff and actively supervising the common Tier 1 implementation plan. Moreover, research indicates that when school principals are actively involved by supporting and facilitating school interventions, these are more likely to succeed and become sustainable (Forman et al., 2013; Yeung et al., 2016).

Tier 1 implementation requires that in each school a Leadership team (LT) is formed by two to three teachers who will be trained in the intervention procedures by external coaches. LT members role is to engage and motivate the school staff in the design and implementation of Tier 1, to lead by example and promote the philosophy of SWPBIS by their words and actions and finally to design the eight core elements of Tier 1. The School's Management Team role is: to act as role models and promoting the vision and values of the school, to encourage and praise any efforts of staff and school LT that enhances the collective approach, to collaborate continuously and actively with the LT members and to make any necessary arrangements on the school agenda.

\subsection{Clarifying expected behavior}

The second step of implementation includes the formulation and formulation of a common set of values which will be directly related to the vision of the school (Bambara \& Kern, 2005; Nelen et al., 2020). $\mathrm{n}$ fact, values are the school unit's guidelines for the social behavior that students are expected to develop. Values should be worded in specific words, taking into account the following criteria: a) be positively worded, b) be worded very quickly, e.g. in a 


\section{2nd world conference on research in SOCIAL SCIENCES}

19-21 March, 2021

Budapest, Hungary

word, c) to be inclusive, that is, a set of behaviors to belong to a value and d) to answer the question: "How do we want children to behave at school in order to succeed?" (MO-SWPBS Handbook, 2020).

Both the vision and the values of the school should be addressed to the whole school community and aim to improve the learning outcomes of all students in the school (T. Lewis \& Sugai, 1999). In schools it is suggested: a) the choice of expected behaviors to be based on data, b) behaviors to relate to specific areas of the school, and c) to take into account their particular needs(Geoff Colvin \& Sugai, 2017). Values are directly related to the vision and mission of the school and determine the behavior of all students. Teachers are encouraged to work with students to create motivational slogans that promote school values. These can be posted in the common areas and classrooms of the school unit, in order to inspire the whole educational community (MO-SWPBS Handbook, 2020).

\subsection{Teaching expected behavior}

As mentioned above, each school unit identifies three school expectations or school values, which determine how a student should behave in the school environment. Expected social behaviors include the social skills and routines that students should demonstrate and follow accordingly in all school settings. Both social skills and routines should match school's students and staff characteristics (T. Lewis \& Sugai, 1999).

Each teacher can follow his own routines in his class, which he can enrich with one or two which are applied jointly in the school. Some examples are: a) the arrival of students in the classroom and their departure from it, b) the formation of a line during the morning gathering, c) the warning signal and d) the movement by school bus. Social behaviors are expressed in a short and positive way and using a verb in the active voice, they must be observable, measurable, appropriate for the age of the students and not overlap with each other, ie by the other behaviors suggested by the school (T. Lewis \& Sugai, 1999).

\subsection{Encouraging expected behavior}

Important elements in SWPBIS implementation are the recognition and encouragement of students when they behave in accordance with the expected social behaviors (Lewis \& Sugai, 1999). As a result, positive interactions and relationships are built between teachers and students which then contribute to school climate's improvement (McIntosh \& Lane, 2019; Rudasill, Snyder, Levinson, \& L. Adelson, 2018).

The fifth core feature of Tier 1 is the implementation of a common system for recognizing and enhancing positive behavior (Bohanon et al., 2006; Bohanon \& Wu, 2014; Estrapala, Rila, \& Bruhn, 2020), such as reward systems (Ivy, Meindl, Overley, \& Robson, 2017; Kazdin, 2012; Lewis \& Sugai, 1999). Creating and maintaining a common recognition system results in: a) increased chance that students repeat expected behaviors, b) attention of all school community members on common and expected behaviors, c) development of a positive school climate, d) teachers focus on teaching, encouraging and supporting students to adopt the expected behaviors and e) active participation of students in the school environment and greater chances of behaving in a positive manner in other environments (Sugai \& Horner, 2009). The common system of recognition adopted by schools may record both each student's and whole class progress in positive behavior. 


\section{2nd world conference on research in SOCIAL SCIENCES}

19-21 March, 2021

Budapest, Hungary

Teachers' contribution in Tier 1 implementation is critical because they are required to reward students and collect data when students behave in positive way. Teachers' positive feedback is a core element of SWPBIS. This may be a verbal praise of the student by the teacher, a material reinforcement that the teacher imparts to the student, or even a combination of the two previous types of response (Narhi, Kiiski, Peitso, \& Savolainen, 2015; Reinke, Herman, \& Stormont, 2012; Sugai \& Simonsen, 2020). Verbal praise should be specific, i.e. it should refer to the positive oral statements of teachers which are followed by some expected social behavior by the student (Markelz et al., 2021). Rewards can be either material or social, such as participating in an activity. Material reinforcements are not offered as a bribe (Burden \& Fraser, 1994; McIntosh, Filter, Kelm, Ryan, \& Sugai, 2009), because by definition they are offered to persuade a person to act in favor of another, usually within an illegal and dishonest way and even before the behavior occurs. In contrast, material reinforcements are offered as a reward when children demonstrate the expected behaviors (Akin-Little \& Little, 2009). Recognizing and rewarding behaviors can affect both individual students and the whole class (MO-SWPBS Handbook, 2020).

\subsection{Discouraging unexpected behavior}

Despite Tier 1 implementation, students' behavior problems are more likely to persist. For this reason teachers are invited to develop a common approach to dealing with the above behaviors (Lewis \& Sugai, 1999). For students this may be considered as an additional opportunity to learn and for teachers to teach again the expected behaviors. The correction of behavioral problems using teaching methods interrupts the unwanted behavior occurrence, preserves the positive school climate, places emphasis on school values, provides the student to practice his/her social skills and increases the likelihood of the desired behavior to occur in the future (Dretske, 1991).

Tier's 1 sixth core feature requires the definition of unexpected behaviors, so that teachers can manage them effectively. Unexpected behaviors should be categorized into mild and severe, so that they can be managed accordingly (Hannigan \& Hauser, 2015; Newcomer, Powers, \& Lewis, 2002). School teams should also develop specific protocols with consequences that will be applied to specific student behavior violations (T. Lewis \& Sugai, 1999). School policies should be applied to all students and be applied in a consistent way.

\subsection{Ongoing monitoring}

Data collection and analysis for decision making in order to continuously improve the school is the seventh core element of Tier 1. The desired improvement should be based on the specific data of each school, so that school staff apply practices directly related to school's needs. School Leadership teams collaborate with external coaches to monitor the way in which Tier 1 procedures are applied and to evaluate schools' improvement plan. In particular, the data collection aims to investigate the quality and positive results of practices and actions that are applied by the staff of the school and are reflected in the desired results. Data collection takes place at the beginning and end of each school year. Additional data sources are the minutes of school leadership teams and teaching staff's meetings, as well as school's annual action plan.

Recognition for both individual students and the whole class can be recorded either daily or weekly on a reward record sheet. Whole class reward recordings are considered of a greater 


\section{2nd world conference on research in SOCIAL SCIENCES}

19-21 March, 2021

Budapest, Hungary

pedagogical effect when they are exhibited in a prominent place within the classroom. It is also important that students in the class are informed about how many of them did better than last week.

\subsection{Professional learning}

One of the most important roles of SWPBIS Leadership teams is to provide quality professional learning activities and development events to enhance teachers efficient Tier 1 implementation. However, prior to providing training or technical assistance to school teams, SWPBIS Leadership teams should assess the school's level of content and implementation readiness (Lewis, Barrett, Sugai, \& Horner, 2010). SWPBIS is a complex process and it requires district and school leadership teams to move through five phases (Fixsen et al., 2005): a) exploration and adoption, which is about securing agreement with school community members to pursue a change in practice and self-assessing capacity to implement, b) installation, referring to establishing the necessary initial systems, data-decisions, and practices to implement Tier 1 to the degree change in student behavior is evident, c) initial implementation, which is targeting a Tier 1 element for all school community members to commence implementation, d) full implementation, referring to operating all systemic components and interventions that are responsive to patterns noted within the school's data, d) innovation and sustainability, requiring revising and updating practices and systems to sustain positive outcomes in student behaviors.

SWPBIS's coordinators and trainers oversee the professional development, implementation, and evaluation efforts of all participating schools. They are also responsible for delivering effective professional development and training skills, coordinating coach monthly meetings and providing content that leads to measurable outcomes among participating school teams (Lewis, Barrett, Sugai, \& Horner, 2010). Furthermore, external coaches are recommended within the SWPBIS professional development process. Their role is to assist and support school teams during professional development events (Lohrmann, Martin, \& Patil, 2012) and activities and make sure Tier 1 procedures are implemented with fidelity (Andreou, McIntosh, Ross, \& Kahn, 2014).

\section{Tier 1 implementation by 30 Greek primary schools}

As mentioned above, 30 primary schools from the Regional Directorate of Primary and Secondary Education of Central Macedonia, Greece, participate in the European research project Erasmus+ Strategic Partnerships KA3 "Building Positive, Inclusive and Equal Learning Environments through the Promotion of Positive Behaviors" (606687-EPP-1-20182-CY-EPPKA3-PI-POLICY). The schools are supervised by two School Counselors. Before project's kick off, the school principals were informed about the features and requirements of the intervention. Then the school principals informed the teaching staff about their intention to participate in the project. Schools were accepted to join the project if $80 \%$ of their teaching staff agreed to implement the Tier 1 procedures.

The 30 schools were divided into two equal groups: the experimental and the control group. Three external coaches, who participate in the scientific team of the project on behalf of the Aristotle University of Thessaloniki, were trained on SWPBIS approach and Tier 1 core features. Five schools from both experimental and control groups were assigned to each 


\section{2nd world conference on research in SOCIAL SCIENCES}

19-21 March, 2021

Budapest, Hungary

external coach. First, teachers from the experimental group were trained in special meetings by the external coaches and formed their school leadership teams. Principals joined the school teams. School leadership teams were assigned to implement the preliminary steps of Tier 1 intervention and propose to the rest teaching staff the philosophy, the vision, the values and the desired behaviors to teach to their students. The two School Counselors provided feedback on the school improvement plan, participated in school leadership teams and school staff meetings and trainings, supported the implementation of the collective approach and remained informed about the progress of Tier 1 implementation. During the school year $2019-2020$ school staff from the experimental group was trained. The next school staff year the school staff from the control group waw trained. By the end of January 2020 schools from experimental group and by the end of January 2021 those from the control group had successfully described the vision and values of their schools and defined a set of three to five expected social behaviors related to the above values. Furthermore, school staff had informed families of their students about Tier 1 implementation procedures, designed their social behavior teaching strategies according to lesson plans and established a common rewards system. Teachers started teaching social behaviors during their classes and together with students they created educational material, such as: lesson plans, posters, illustrated slogans, multimedia presentations and videos in order to promote their common vision, values and expected behaviors. Finally, teachers collected data to monitor the progress of the intervention and uploaded the educational material on the pbiseurope.org website.

However, Tier 1 implementation was unexpectedly interrupted in March 2020 due to the pandemic. In some schools, teachers linked their school values to the requirements of distance learning and taught to children how to stay safe in the new digital environment. In addition, teachers at many schools developed values and rules for the expected student behaviors keep protected by COVID-19 on their return to school.

The European project's research group uses the Tiered Fidelity Inventory (TFI) (Algozzine et al., 2014), which is the newest and one of the most comprehensive and empirically-validated measures of SWPBIS implementation fidelity (McIntosh et al., 2017) in order to examine the extent to which core features and procedures of Tier 1 were present in the 30 participating schools in the Erasmus + KA3 project titled: "Building School-Wide Inclusive, Positive and Equitable Learning Environments Through A Systems-Change Approach", and if SWPBIS Tier 1 was implemented with fidelity. Results are expected by the end of June 2021.

\section{Conclusion}

By taking part in the Erasmus+ KA3 project titled: "Building School-Wide Inclusive, Positive and Equitable Learning Environments Through A Systems-Change Approach", 30 Greek primary schools started to implement SWPBIS's Tier 1 procedures during 2020 and 2021. In total, 3799 students and 478 teachers participate in the project. Three external coaches from Aristotle University of Thessaloniki and two School Counsellors from the Regional Directorate of Primary and Secondary Education of Central Macedonia, Greece, provide guidance, support and training to teaching staff so that Tier 1 procedures are implemented. So far, school staff has set the common vision, values, established reward systems for students who behave according to expected behaviors and collects data. Because of COVID-19 


\section{2nd world conference on research in SOCIAL SCIENCES}

19-21 March, 2021

Budapest, Hungary

pandemic, teaching staff adapted some of their school values and expected behavior accordingly. The project's team will use a range of tools to check if SWPBIS Tier 1 implementation procedures and core features were implemented with fidelity and whether school climate in the 30 participating schools was improved. Results are expected by the end of the school year $2020-2021$.

\section{Funding}

This project has been funded with support from the European Commission. This publication reflects the views only of the author, and the Commission cannot be held responsible for any use which may be made of the information contained therein. Project Number: 606687-EPP-1-2018-2-CY-EPPKA3-PI-POLICY.

\section{References}

Akin-Little, A., \& Little, S. G. (2009). The true effects of extrinsic reinforcement on "intrinsic" motivation. In School Psychology. Behavioral interventions in schools: Evidence-based positive strategies. (pp. 73-91). https://doi.org/10.1037/11886-005

Algozzine, B., Barrett, S., Eber, L., George, H., Horner, R., Lewis, T., ... Sugai, G. (2014). School-wide PBIS Tiered Fidelity Inventory (pp. 1-31). pp. 1-31. Retrieved from https://www.pbis.org

Andreou, T. E., McIntosh, K., Ross, S. W., \& Kahn, J. D. (2014). Critical Incidents in Sustaining School-Wide Positive Behavioral Interventions and Supports. The Journal of Special Education, 49(3), 157-167. https://doi.org/10.1177/0022466914554298

Bambara, L. M., \& Kern, L. (2005). Individualized supports for students with problem behaviors: Designing positive behavior plans. Guilford Press.

Barrett, S. B., Bradshaw, C. P., \& Lewis-Palmer, T. (2008). Maryland Statewide PBIS Initiative: Systems, Evaluation, and Next Steps. Journal of Positive Behavior Interventions, 10(2), 105-114. https://doi.org/10.1177/1098300707312541

Bohanon, H., Fenning, P., Carney, K. L., Minnis-Kim, M. J., Anderson-Harriss, S., Moroz, K. B., ... Pigott, T. D. (2006). Schoolwide Application of Positive Behavior Support in an Urban High School: A Case Study. Journal of Positive Behavior Interventions, 8(3), 131-145. https://doi.org/10.1177/10983007060080030201

Bohanon, H., \& Wu, M. J. (2014). Developing buy-in for positive behavior support in secondary settings. Preventing School Failure, 58(4), 223-229. https://doi.org/10.1080/1045988X.2013.798774

Bradshaw, C. P., Mitchell, M. M., \& Leaf, P. J. (2010). Examining the effects of schoolwide positive behavioral interventions and supports on student outcomes: Results from a randomized controlled effectiveness trial in elementary schools. Journal of Positive Behavior Interventions, 12(3), 133-148. https://doi.org/10.1177/1098300709334798

Bradshaw, C. P., Reinke, W. M., Brown, L. D., Bevans, K. B., \& Leaf, P. J. (2008). Implementation of School-Wide Positive Behavioral Interventions and Supports (PBIS) in Elementary Schools: Observations from a Randomized Trial. Education and 


\section{2nd world conference on research in SOCIAL SCIENCES}

19-21 March, 2021

Budapest, Hungary

Treatment of Children, 31(1), 1-26. https://doi.org/10.1353/etc.0.0025

Burden, R., \& Fraser, B. (1994). Examining Teachers' Perceptions of Their Working Environments: Introducing the School Level Environment Questionnaire. Educational Psychology in Practice, 10(2), 67-73. https://doi.org/10.1080/0266736940100201

Carr, E. G., Dunlap, G., Horner, R. H., Koegel, R. L., Turnbull, A. P., Sailor, W., ... Fox, L. (2002). Positive Behavior Support: Evolution of an Applied Science. Journal of Positive Behavior Interventions, 4, 4-17. https://doi.org/10.1177/109830070200400102

Colvin, G., Kameenui, E. J., \& Sugai, G. (1993). Reconceptualizing behavior management and school-wide discipline in general education. Education and Treatment of Children, 16(4), 361-381. Retrieved from http://www.jstor.org/stable/42899326

Colvin, Geoff, \& Sugai, G. (2017). Seven steps for developing a proactive schoolwide discipline plan: A guide for principals and leadership teams. Corwin Press.

Dretske, F. I. (1991). Explaining behavior: Reasons in a world of causes. MIT press.

Estrapala, S., Rila, A., \& Bruhn, A. L. (2020). A Systematic Review of Tier 1 PBIS Implementation in High Schools. Journal of Positive Behavior Interventions. https://doi.org/10.1177/1098300720929684

Fixsen, D. L., Naoom, S. F., Blase, K. A., Friedman, R. M., Wallace, F., Burns, B., ... Barwick, M. (2005). Implementation research: A synthesis of the literature.

Forman, S. G., Shapiro, E. S., Codding, R. S., Gonzales, J. E., Reddy, L. A., Rosenfield, S. A., ... Stoiber, K. C. (2013). Implementation science and school psychology. School Psychology Quarterly, Vol. 28, pp. 77-100. https://doi.org/10.1037/spq0000019

Hannigan, J. D., \& Hauser, L. (2015). The PBIS tier one handbook: A practical approach to implementing the champion model. Corwin Press.

Horner, R. H., Sugai, G., Smolkowski, K., Eber, L., Nakasato, J., Todd, A. W., \& Esperanza, J. (2009). A randomized, wait-list controlled effectiveness trial assessing school-wide positive behavior support in elementary schools. Journal of Positive Behavior Interventions, 11(3), 133-144. https://doi.org/10.1177/1098300709332067

Horner, Robert H., \& Sugai, G. (2015). School-wide PBIS: An Example of Applied Behavior Analysis Implemented at a Scale of Social Importance. Behavior Analysis in Practice, 8(1), 80-85. https://doi.org/10.1007/s40617-015-0045-4

Ivy, J. W., Meindl, J. N., Overley, E., \& Robson, K. M. (2017). Token Economy: A Systematic Review of Procedural Descriptions. Behavior Modification, 41(5), 708-737. https://doi.org/10.1177/0145445517699559

Kazdin, A. (2012). The token economy: A review and evaluation. Springer Science \& Business Media.

Lewis, T. J., Barrett, S., Sugai, G., \& Horner, R. H. (2010). Blueprint for schoolwide positive behavior support training and professional development. National Technical Assistance Center on Positive Behavior Interventions and Support, Eugene.

Lewis, T., \& Sugai, G. (1999). Effective Behavior Support: A Systems Approach to Proactive Schoolwide Management. Focus on Exceptional Children, 31(6), 1-31. Retrieved from 


\section{2nd world conference on research in SOCIAL SCIENCES}

19-21 March, 2021

Budapest, Hungary

https://librarylink.uncc.edu/login?url=http://search.ebscohost.com.librarylink.uncc.edu $/$ login. asp $x$ direct=true $\& \mathrm{db}=\mathrm{ehh} \& \mathrm{AN}=1859974 \&$ site=ehost-live $\&$ scope $=$ site

Lohrmann, S., Martin, S. D., \& Patil, S. (2012). External and Internal Coaches' Perspectives About Overcoming Barriers to Universal Interventions. Journal of Positive Behavior Interventions, 15(1), 26-38. https://doi.org/10.1177/1098300712459078

Markelz, A., Riden, B., Floress, M. T., Balint-Langel, K., Heath, J., \& Pavelka, S. (2021). Teachers' Use of Specific, Contingent, and Varied Praise. Journal of Positive Behavior Interventions, 1098300720988250. https://doi.org/10.1177/1098300720988250

McIntosh, K., Filter, K., Kelm, J., Ryan, C., \& Sugai, G. (2009). Principles of sustainable prevention: Designing scale- up of School- wide Positive Behavior Support to promote durable systems. Psychology in the Schools, 47, 5-21. https://doi.org/10.1002/pits.20448

McIntosh, K., \& Lane, K. L. (2019). Advances in Measurement in School-Wide Positive Behavioral Interventions and Supports. Remedial and Special Education, 40(1), 3-5. https://doi.org/10.1177/0741932518800388

McIntosh, K., Massar, M. M., Algozzine, R. F., George, H. P., Horner, R. H., Lewis, T. J., \& Swain-Bradway, J. (2017). Technical Adequacy of the SWPBIS Tiered Fidelity Inventory. Journal of Positive Behavior Interventions, 19(1), 3-13. https://doi.org/10.1177/1098300716637193

McKevitt, B. C., \& Braaksma, A. D. (2004). Best Practices in Developing a Positive Behavior Support System at the School Level. Best Practices in School Psychology V, 3, 735-748.

MO-SWPBS Handbook. (2020). Missouri Schoolwide Tier 1 Implementation Guide. Retrieved from https://pbismissouri.org/wp-content/uploads/2020/03/2019-20-SWPBSTier1-IG-3.26.20.pdf

Narhi, V., Kiiski, T., Peitso, S., \& Savolainen, H. (2015). Reducing disruptive behaviours and improving learning climates with class-wide positive behaviour support in middle schools. European Journal of Special Needs Education, 30(2), 274-285. Retrieved from www.tandf.co.uk/journals/titles/08856257.asp\%5Cnhttp://ovidsp.ovid.com/ovidweb.cgi? $\mathrm{T}=\mathrm{JS} \& \mathrm{PAGE}=\mathrm{reference} \& \mathrm{D}=$ emed13\&NEWS $=\mathrm{N} \& \mathrm{AN}=2014948135$

Nelen, M. J. M., Blonk, A., Scholte, R. H. J., \& Denessen, E. (2020). School-Wide Positive Behavior Interventions and Supports: Fidelity of Tier 1 Implementation in 117 Dutch Schools. Journal of Positive Behavior Interventions, 22(3), 156-166. https://doi.org/10.1177/1098300719879621

Newcomer, L. L., Powers, L. J., \& Lewis, T. J. (2002). Policies and Procedures to Develop Effective School-Wide Discipline Practices at the Elementary School Level. Case/cbd Mini-Library Serieson Safe, Drug-Free, and Effective Schools. Council for Exceptional Children.

Reinke, W. M., Herman, K. C., \& Stormont, M. (2012). Classroom-Level Positive Behavior Supports in Schools Implementing SW-PBIS. Journal of Positive Behavior Interventions, 15(1), 39-50. https://doi.org/10.1177/1098300712459079

Rudasill, K. M., Snyder, K. E., Levinson, H., \& L. Adelson, J. (2018). Systems View of School Climate: a Theoretical Framework for Research. Educational Psychology Review, 


\section{2nd world conference on research in SOCIAL SCIENCES}

19-21 March, 2021

Budapest, Hungary

30(1), 35-60. https://doi.org/10.1007/s10648-017-9401-y

Sugai, G., \& Horner, R. (2002). The Evolution of Discipline Practices: School-Wide Positive Behavior Supports. Child \& Family Behavior Therapy, 24(1-2), 23-50. https://doi.org/10.1300/J019v24n01_03

Sugai, G., \& Horner, R. H. (2008). What We Know and Need to Know about Preventing Problem Behavior in Schools. Exceptionality, 16(2), 67-77. https://doi.org/10.1080/09362830801981138

Sugai, G., \& Horner, R. H. (2009). Responsiveness-to-Intervention and School-Wide Positive Behavior Supports: Integration of Multi-Tiered System Approaches. Exceptionality. https://doi.org/10.1080/09362830903235375

Sugai, G., \& Simonsen, B. (2020). Reinforcement Foundations of a Function-Based Behavioral Approach for Students With Challenging Behavior. Beyond Behavior, 1074295620902444. https://doi.org/10.1177/1074295620902444

Van Camp, A. M., Wehby, J. H., Copeland, B. A., \& Bruhn, A. L. (2020). Building From the Bottom Up: The Importance of Tier 1 Supports in the Context of Tier 2 Interventions. Journal of Positive Behavior Interventions. https://doi.org/10.1177/1098300720916716

Yeung, A. S., Craven, R. G., Mooney, M., Tracey, D., Barker, K., Power, A., ... Lewis, T. J. (2016). Positive Behavior Interventions: the Issue of Sustainability of Positive Effects. Educational Psychology Review, 28(1), 145-170. https://doi.org/10.1007/s10648-0159305-7 